\title{
Effects of different surgical procedures on stress hormones, vascular inflammatory factors, tissue damage inflammatory factors in patients with renal calculi.
}

\author{
Shang-wen Xiao" ${ }^{1 \#}$, Fu Shi ${ }^{2 \#}$, Bao-hai $\mathrm{Xu}^{3 \text { * }}$ \\ ${ }^{1}$ Department of Urology, Ankang Hospital of Traditional Chinese Medicine, Ankang City, Shanxi Province, PR China \\ ${ }^{2}$ Department of Urology, the Seventh Affiliated Hospital of Sun Yat-sen University, Shenzhen City, Guang Dong \\ Province, PR China \\ ${ }^{3}$ Department of Urology, Ankang Central Hospital, Ankang City, Shanxi Province, PR China
}

\#These authors contributed equally

\begin{abstract}
Objective: To investigate the effects of Percutaneous Nephroscope Ultrasonic Lithotripsy (PNUL) and Percutaneous Nephroscope Pneumatic Lithotripsy (PNPL) on stress hormones, vascular inflammatory factors and tissue damage inflammatory factors in patients with renal calculi.

Methods: 120 patients with renal calculi in our hospital from January 2016 to June 2017 were divided randomly into observation group (PNUL group) and control group (PNPL group), 60 cases in each group. At $24 \mathrm{~h}$ before and after operation, the levels of Angiotensin-II (Ang-II), Adrenocorticotropic Hormone (ACTH), Cortisol (Cor), Norepinephrine (NE), Prostaglandin E2 (PEG2), Substance P (SP), Bradykinin (BK), Nitric Oxide (NO), Advanced Oxidation Protein Products (AOPP) and Lipid Peroxide (LPO) were compared in all patients.

Results: There were no statistical differences in the levels of Ang-II, ACTH, Cor, NE, PEG2, SP, BK, NO, AOPP and LPO before operation between the two groups $(P>0.05)$; at $24 \mathrm{~h}$ after operation, the level of each index was higher than that before operation in both groups. The levels of above-mentioned indexes in the observation group were $(53.38 \pm 4.65 \mathrm{pg} / \mathrm{ml}),(27.28 \pm 3.06 \mathrm{pg} / \mathrm{ml}),(172.76 \pm 10.65 \mathrm{ng} / \mathrm{ml})$, $(276.19 \pm 24.12 \mathrm{ng} / \mathrm{ml}),(161.51 \pm 16.70 \mathrm{pg} / \mathrm{ml}),(4.71 \pm 0.51 \mu \mathrm{g} / \mathrm{ml}),(8.32 \pm 0.64 \mu \mathrm{g} / \mathrm{L}),(13.42 \pm 1.56$ $\mu \mathrm{mol} / \mathrm{L}),(202.38 \pm 31.74 \mu \mathrm{mol} / \mathrm{L}),(4.29 \pm 0.63 \mathrm{mmol} / \mathrm{ml})$ respectively, were lower than those during the same period in the control group and the differences were statistically significant $(P<0.05)$.

Conclusion: PNUL has a less effect on stress hormones, vascular inflammatory factors, tissue damage inflammatory factors in patients with renal calculi and has a smaller trauma than PNPL. Thus, PNUL is recommended to be widely used in clinical practice.
\end{abstract}

Keywords: Renal calculus, Stress hormones, Inflammatory factor.

Accepted on November 13, 2017

\section{Introduction}

Renal calculi are clinically common urinary system disorders. Patients with renal calculi often present with clinical symptoms such as renal colic, hematuria and urination disorders; in addition to above-mentioned symptoms, over half of them are also accompanied by different degrees of lumbagos, which seriously affect daily lives of patients [1,2]. Prolonged retention of renal calculi can lead to atrophy of nephron and in more severe cases, it can lead to renal failure [3]. Timely surgery is the main method for clinical treatment of renal calculi when expectant treatment fails. In recent years, with the development of minimally invasive surgical technology in urology, there is a tendency for traditional open lithotomy to be replaced gradually by minimally invasive lithotomy. Common surgical techniques include minimally invasive percutaneous nephroscope lithotripsy, Percutaneous Nephroscope Ultrasonic Lithotripsy (PNUL) and postlaparoscope pelviolithotomy. Clinically, so long as surgical techniques are selected according to surgical indication, the clinical efficacies of the abovementioned surgical techniques can be affirmed [4]. PNUL and Percutaneous Nephroscope Pneumatic Lithotripsy (PNPL) are the two main lithotomies in China, have the advantages of clear surgical views, convenient and fast operations and high stone free rate, and the clinical efficacy of either has been generally recognized in clinical practice [5]. However, few studies have assessed the effects of the two surgical techniques on physical stress and inflammatory factors [5,6]. As a 
traumatic therapeutic method, operations will inevitably lead to stress reaction in patients by activating the adrenalin, angiotensin system or stimulating the hypothalamo-pituitaryadrenal axis etc. [7,8]. Inflammatory reaction is an important mechanism in stress reaction, and an inevitable pathophysiological process after operation as well. Because the changes in stress and inflammatory state can further affect the postoperative rehabilitation of patients, stress and inflammatory reaction have also become important indexes to operative efficacy $[9,10]$. In this study, the effects of PNUL and PNPL on stress hormones and inflammatory factors in patients with renal calculi were compared and analysed in order to provide a scientific basis for the optimization of operative selection.

\section{Data and Methods}

\section{General data}

120 patients with renal calculi in our hospital from January 2016 to June 2017 were randomly divided into observation group and control group, 60 cases in each group. The observation group received PNUL and the control group received PNPL. Selective requirements were as follows:

Inclusive criteria: Patients were diagnosed with renal calculi by uronoscopy and ultrasonic imaging inspection; the maximum diameter of single renal calculus was more than $2 \mathrm{~cm}$; there was no contraindication for operative treatment; patients had been approved by the Ethics Committee in our hospital (No:AK15092853) and had signed the informed consents.

Exclusive criteria: Renal calculi with severe nephroptosis; renal calculi patients with concurrent hepatorenal dysfunction, universal hemorrhagic disease, endocrine diseases or mental obstructive diseases; conditions of hypertension and diabetes mellitus were uncontrolled.

Rejection criteria: Patients who asked to quit the study, or were automatically discharged or abandoned the treatment were rejected.

The general data of patients such as gender, age and disease course were compared between the two groups, the differences were not statistically significant $(\mathrm{P}>0.05)$, and all general data were comparable. The detailed information was shown in Table 1.

\section{Operative methods}

The patients in the two groups were given general endotracheal anaesthesia. At first, after retrograde from lithotomy position, F5 or F6 ureteral catheter was carried to affected pelvis renalis, "artificial hydronephrosis" was established by injecting physiological saline; the lumbar regions of patients were elevated, meanwhile, patients were put in the prone position, and then, percutaneous puncture was performed in intercostal locations of patients under the condition of ultrasonic dynamic monitoring, after puncture needle reached into targeted renal calices, core needle was removed. When there was a urinary discharge, Zebra wire was led in immediately. Then, skin was incised by operating knife and fascial dilator was put in. After fascia was dilated to location F16, Peel-Away Introducer Set was placed in and percutaneous renal pathway was established. Then, percutaneous nephroscope set was put in, and at this moment, the size, number and location of renal calculus were observed. In the observation group, ultrasonic lithotrite was used to dilate and fragmentate renal calculi, then fragmented calculi were absorbed and removed; in the control group, pneumatic lithotrite was used to fragmentate renal calculi and fragmented calculi were drawn off by vacuum aspiration technique.

Table 1. Comparison of the general data between the two groups (mean $\pm S D)$

\begin{tabular}{|c|c|c|c|c|}
\hline Items & $\begin{array}{l}\text { Observation } \\
\text { group }(n=60)\end{array}$ & $\begin{array}{l}\text { Control } \\
\text { group }(n=60)\end{array}$ & $x^{2} / t$ & $\mathbf{P}$ \\
\hline Age & $41.90 \pm 5.88$ & $42.01 \pm 6.10$ & 0.101 & 0.920 \\
\hline $\begin{array}{l}\text { Gender (Male/ } \\
\text { female) }\end{array}$ & $38 / 22$ & $39 / 21$ & 0.036 & 0.849 \\
\hline $\begin{array}{l}\text { Disease } \\
\text { course (y) }\end{array}$ & $1.13 \pm 0.53$ & $1.15 \pm 0.50$ & 0.213 & 0.832 \\
\hline $\begin{array}{l}\text { Diameter of } \\
\text { renal calculus } \\
(\mathrm{cm})\end{array}$ & $3.31 \pm 0.59$ & $3.28 \pm 0.49$ & 0.303 & 0.762 \\
\hline $\begin{array}{l}\text { Number of } \\
\text { renal calculus }\end{array}$ & & & 0.051 & 0.822 \\
\hline Solitary & 12 & 13 & & \\
\hline Multiple & 48 & 47 & & \\
\hline $\begin{array}{l}\text { Location of } \\
\text { renal calculus }\end{array}$ & & & 0.307 & 0.858 \\
\hline Left kidney & 11 & 10 & & \\
\hline Right kidney & 17 & 15 & & \\
\hline Double kidney & 32 & 35 & & \\
\hline
\end{tabular}

\section{Main outcome measure}

At $24 \mathrm{~h}$ before and after operation, fasting venous blood in the morning was collected from patients in both groups respectively and centrifuged at the rate of $3000 \mathrm{r} / \mathrm{min}$ for 10 min. After centrifugation of blood, the following indexes were detected: (1) Stress hormones: Angiotensin-II (Ang-II), Adrenocorticotropic Hormone (ACTH), Cortisol (Cor) and Norepinephrine (NE) were determined by enzyme linked immunosorbent assay. (2) Vascular inflammatory factors: Prostaglandin E2 (PEG2), Substance P (SP) and Bradykinin (BK) were determined by enzyme linked immunosorbent assay. (3) Tissue damage inflammatory factors: Nitric Oxide (NO), Advanced Oxidation Protein Products (AOPP) and Lipid Peroxide (LPO) were determined by spectrophotometer. All kits were purchased from Shanghai Enzyme-linked 
Effects of different surgical procedures on stress hormones, vascular inflammatory factors, tissue damage inflammatory factors in patients with renal calculi

Biotechnology Co., Ltd. and Nanjing Jiancheng Bioengineering Institute.

Table 2. Comparison of stress hormones between the two groups (mean $\pm S D)$.

\begin{tabular}{|c|c|c|c|c|c|c|c|}
\hline Time & Group & $\begin{array}{l}\text { Number } \\
\text { cases }\end{array}$ & of & Ang-II (pg/ml) & АCTH (pg/ml) & Cor (ng/ml) & NE (ng/ml) \\
\hline \multirow[t]{4}{*}{ Before operation } & Observation group & 60 & & $45.52 \pm 3.60$ & $20.26 \pm 1.43$ & $160.60 \pm 15.63$ & $246.14 \pm 21.23$ \\
\hline & Control group & 60 & & $45.48 \pm 3.57$ & $20.30 \pm 1.50$ & $162.73 \pm 15.14$ & $245.30 \pm 21.28$ \\
\hline & $\mathrm{t}$ & & & 0.061 & 0.150 & 0.758 & 0.216 \\
\hline & $P$ & & & 0.951 & 0.881 & 0.450 & 0.829 \\
\hline \multirow{4}{*}{$\begin{array}{l}\text { At } 24 \quad h \text { after } \\
\text { operation }\end{array}$} & Observation group & 60 & & $53.38 \pm 4.65^{a}$ & $27.28 \pm 3.06^{a}$ & $172.76 \pm 10.65^{a}$ & $276.19 \pm 24.12^{a}$ \\
\hline & Control group & 60 & & $62.93 \pm 4.80^{a}$ & $35.46 \pm 3.96^{a}$ & $230.95 \pm 13.45^{a}$ & $352.39 \pm 33.05^{a}$ \\
\hline & $\mathrm{t}$ & & & 11.069 & 12.661 & 26.273 & 14.426 \\
\hline & $\mathrm{P}$ & & & 0.000 & 0.000 & 0.000 & 0.000 \\
\hline
\end{tabular}

Note: Compared with the preoperative levels in this group, ${ }^{\mathrm{a} P}<0.05$.

\section{Statistical analysis}

The statistical analysis was performed by using the SPSS 19.0 statistical software. The numerical data were expressed as frequency (n) or percentage (\%), the $\chi^{2}$ test was used for group comparison, the measurement data were expressed as mean \pm standard deviation, the independent T-test was used for group comparison and the paired t-test was used for intra-group comparison. Differences with a P value of less than 0.05 were considered statistically significant.

\section{Results}

\section{Comparison of stress hormones between the two groups}

Before operation, there were no statistically significant differences in the levels of Ang-II, ACTH, Cor and NE between the two groups $(\mathrm{P}>0.05)$; at $24 \mathrm{~h}$ after operation, the levels of Ang-II, ACTH, Cor and NE in the two groups were significantly higher than those before operation, the levels of Ang-II, ACTH, Cor and NE in the control group were higher than those in the observation group, and the differences were statistically significant $(\mathrm{P}<0.05)$. The detailed information is shown in Table 2.

\section{Comparison of vascular inflammatory factors between the two groups}

Before operation, there were no statistically significant differences in the levels of PEG2, SP and BK between the two groups ( $\mathrm{P}>0.05)$; at $24 \mathrm{~h}$ after operation, the levels of PEG2, SP and BK in patients in the two groups were significantly higher than those before operation, the levels of PEG2, SP and $\mathrm{BK}$ in the control group were higher than those in the observation group, and the differences were statistically significant $(\mathrm{P}<0.05)$. The detailed information is shown in Table 3.

Table 3. Comparison of vascular inflammatory factors between the two groups (mean $\pm S D)$.

\begin{tabular}{|c|c|c|c|c|c|c|c|}
\hline Time & Group & $\begin{array}{l}\text { Number } \\
\text { of cases }\end{array}$ & $\begin{array}{l}\text { PEG2 } \\
\text { (pg/ml) }\end{array}$ & & $\begin{array}{l}\text { SP } \\
(\mu \mathrm{g} / \mathrm{ml})\end{array}$ & & $B K(\mu g / L)$ \\
\hline \multirow[t]{4}{*}{$\begin{array}{l}\text { Before } \\
\text { operation }\end{array}$} & $\begin{array}{l}\text { Observatio } \\
\text { n group }\end{array}$ & 60 & $\begin{array}{l}120.37 \\
12.62\end{array}$ & \pm & $\begin{array}{l}3.18 \\
0.39\end{array}$ & \pm & $\begin{array}{l}5.89 \\
0.45\end{array}$ \\
\hline & $\begin{array}{l}\text { Control } \\
\text { Group }\end{array}$ & 60 & $\begin{array}{l}120.34 \\
12.67\end{array}$ & \pm & $\begin{array}{l}3.21 \\
0.27\end{array}$ & \pm & $\begin{array}{l}5.77 \\
0.48\end{array}$ \\
\hline & $\mathrm{t}$ & & 0.013 & & 0.490 & & 1.413 \\
\hline & $P$ & & 0.990 & & 0.639 & & 0.160 \\
\hline \multirow[t]{4}{*}{$\begin{array}{l}\text { At } 24 \mathrm{~h} \text { after } \\
\text { operation }\end{array}$} & $\begin{array}{l}\text { Observatio } \\
\text { n group }\end{array}$ & 60 & $\begin{array}{l}161.51 \\
16.70^{a}\end{array}$ & \pm & $\begin{array}{l}4.71 \\
0.51^{a}\end{array}$ & \pm & $\begin{array}{l}8.32 \\
0.64^{a}\end{array}$ \\
\hline & $\begin{array}{l}\text { Control } \\
\text { Group }\end{array}$ & 60 & $\begin{array}{l}199.95 \\
25.26^{a}\end{array}$ & \pm & $\begin{array}{l}7.01 \\
0.62^{\mathrm{a}}\end{array}$ & \pm & $\begin{array}{l}11.75 \\
1.46^{a}\end{array}$ \\
\hline & $\mathrm{t}$ & & 9.833 & & 22.192 & & 16.667 \\
\hline & $P$ & & 0.000 & & 0.000 & & 0.000 \\
\hline
\end{tabular}

Note: Compared with the preoperative levels in this group, ${ }^{\mathrm{a}}<0.05$.

\section{Comparison of tissue damage inflammatory factors between the two groups}

Before operation, there were no statistically significant differences in the levels of NO, AOPP and LPO between the two groups ( $\mathrm{P}>0.05)$; at $24 \mathrm{~h}$ after operation, the levels of $\mathrm{NO}$, AOPP and LPO in all patients were significantly higher than those before operation, the levels of NO, AOPP and LPO in the control group were higher than those in the observation group, 
and the differences were statistically significant $(\mathrm{P}<0.05)$. The detailed information is shown in Table 4.

Table 4. Comparison of tissue damage inflammatory factors between the two groups (mean $\pm S D$ ).

\begin{tabular}{|c|c|c|c|c|c|}
\hline Time & Group & Number of cases & $\mathrm{NO}(\mu \mathrm{mol} / \mathrm{L})$ & AOPP $(\mu \mathrm{mol} / \mathrm{L})$ & LPO (mmol/ml) \\
\hline \multirow[t]{4}{*}{ Before operation } & Observation group & 60 & $9.36 \pm 0.97$ & $161.50 \pm 21.95$ & $2.70 \pm 0.29$ \\
\hline & Control Group & 60 & $9.34 \pm 1.01$ & $163.91 \pm 24.92$ & $2.67 \pm 0.21$ \\
\hline & $\mathrm{t}$ & & 0.111 & 0.562 & 0.649 \\
\hline & $P$ & & 0.912 & 0.575 & 0.537 \\
\hline \multirow[t]{4}{*}{ At $24 \mathrm{~h}$ after operation } & Observation group & 60 & $13.42 \pm 1.56^{\mathrm{a}}$ & $202.38 \pm 31.74^{a}$ & $4.29 \pm 0.63^{a}$ \\
\hline & Control Group & 60 & $17.86 \pm 1.42^{a}$ & $220.41 \pm 31.78^{a}$ & $7.29 \pm 0.69^{a}$ \\
\hline & $\mathrm{t}$ & & 16.303 & 3.109 & 24.871 \\
\hline & $\mathrm{P}$ & & 0.000 & 0.002 & 0.000 \\
\hline
\end{tabular}

Note: Compared with the preoperative levels in this group, ${ }^{\text {ap }}<0.05$

\section{Discussion}

Renal calculi are one of the frequently occurring diseases in urinary system. In recent years, due to influencing factors such as bad dietary habits, work stress and environmental changes, the invasion of renal calculi increasing to critical situation and its incidence is rising year by year [11]. The clinical symptoms of renal calculi include low back pain, renal colic, paruria and so on. In more severe cases, it can lead to hydronephrosis by urinary tract occlusion, and even cause urinaemia and kidney tumors, so when pain cannot be relieved by drugs or diameter of renal calculus is bigger, operations should first be considered to avoid the deterioration of diseases $[12,13]$. The main operations for the treatment of renal calculi currently include PNUL and PNPL. Although different operative techniques have the same effect in removing calculi, and there is few relevant research about this issue [14]. Therefore, the detection of stress hormones and inflammatory factors have important clinical implications for evaluating the effects of different operative techniques.

Traumatic stimulus caused by operative treatment can be introduced into central nervous system by peripheral nerves, activate renin-angiotensin system and hypothalamo-pituitaryadrenal axis, and then lead to significantly increase in serum stress hormone level. The Ang-II, ACTH, Cor and NE are the representative indexes to stress hormones and important indexes to physical stress reaction, and have many advantages such as fast and easy test methods and good sensitivity [15-17]. Inflammation is an important mechanism in stress reaction, and a postoperative inevitable pathological process as well. Of large number of inflammatory factors, vascular inflammatory factors and tissue damage inflammatory factors are closely associated with inflammatory reaction during stress and have a certain reference value in the evaluation of stress reaction degree [18]. PEG2, SP and BK are inflammatory factors that reflect vascular state: PEG2 as an important physiological active substance in organism can play a important role in regulating and controlling vangiogenesis [19,20]; SP as a vasoactive mediator can dilate blood vessels, improve permeability and cause inflammatory reactions such as edema [21]; BK as a Substance P9 peptide, may also dilate blood vessels, and is closely associated with inflammatory pain [22]. NO, AOPP and LPO are important indexes to tissue damage: NO can regulate the barrier function of vascular endothelial cells, when inflammatory tissue damages are observed, Induced Nitric-Oxide Synthase (INOS) in endothelial cells is activated and produces a large number of NO [23,24]; AOPP is a lipid peroxide produced by increased oxygen radical and decreased antioxidation, and peroxidation can lead to lesion in renal cell membrane [25,26]; LPO is also a lipid peroxide produced by the action of oxygen radical, can be aggregated to cell membrane and vessel wall, and then cause the lesions such as sclerosis and fibrous pathologic changes [27].

The study showed that there were no statistical differences in the levels of Ang-II, ACTH, Cor, NE, PEG2, SP, BK, NO, AOPP and LPO before operation between the two groups $(\mathrm{P}>0.05)$; at $24 \mathrm{~h}$ after operation, the levels of Ang-II, ACTH, Cor, NE, PEG2, SP, BK, NO, AOPP and LPO were higher than those before operation in all patients $(\mathrm{P}<0.05)$, and the levels of each index in the control group was higher than that in the observation group $(\mathrm{P}<0.05)$. The results suggested that there were inflammatory stress reaction caused by operative stimulus in all patients, but PNUL caused less abnormal changes in stress hormones and inflammatory factors than PNPL. That was mainly because the fragmentation of renal calculi by ultrasonic vibration in PNUL effectively avoided the mechanical irritation to renal calices, and then vacuum aspiration technique was used to adsorb and remove fragmented calculi, even micro-calculus could also be aspirated out [27]. Because throughout the procedures, stone forceps and operating mirror had no need to come into and out of the lithotomy pathway repeatedly any more, this technique protected nephridial tissue against damages to the most extent, meanwhile, significantly reduced stimulation of residual 
calculi on kidney [28]. In contrast, because PNPL was more likely to damage the nephridial tissue during the fragmentation of calculi, especially a longer irrigation was needed when removing bigger calculi, and the pressure in pelvis renalis was also increased accordingly, this was better for the absorption of bacterial toxin, and also increased the stimulation on organism $[29,30]$.

In conclusion, PNUL has a less effect on stress hormones, vascular inflammatory factors and tissue damage inflammatory factors in patients with renal calculus and has a smaller trauma than PNPL. Thus, PNUL is recommended to be widely used in clinical practice.

\section{References}

1. Ferraro PM, Robertson W, Unwin R. Renal stone disease. Medicine 2015; 43: 427-430.

2. Guo JC. Observation of the effects of pneumatic lithotripsy under percutaneous nephrolithotomy combined with ultrasound lithotripsy in the treatment of complex renal calculi. China Mod Med 2017; 24: 89-91.

3. ElSheemy MS, Shouman AM, Shoukry AI. Ureteric stents vs. percutaneous nephrostomy for initial urinary drainage in children with obstructive anuria and acute renal failure due to ureteric calculi: a prospective, randomised study. BJU Int 2015; 115: 473-479.

4. Deng QF, Jiang R, Pei LJ. Comparison of digital flexible ureteroscopic lithotripsy and minimally invasive percutaneous nephrolithotomy for renal calculi. J Pract Med 2016; 32: 721-723.

5. Bi X, Liu JM, Pu XY. The comparative study of retroperitoneal laparoscopic pyelolithotomy and percutaneous nephrolithotomy in treating renal pelvic stone. China J Urol 2017; 38: 92-94.

6. El-Nahas AR, Elshal AM, Eltabey NA. Percutaneous nephrolithotomy for staghorn stones: a randomized trial comparing high power holmium laser versus ultrasonic lithotripsy. BJU Int 2016; 118: 307-312.

7. Elnahas AR, Eraky I, Shokeir AA. Percutaneous nephrolithotomy for treating staghorn stones: 10 years of experience of a tertiary-care centre. Arab J Urol 2012; 10: 324-329.

8. Zhan XS, Liu QM, Li WH. Effect of Yiqihuoxue paishiyin combined with levofloxacin on renal calculus and inflammatory state. Chin J Biochem Pharm 2017; 37: 49-51.

9. Elderwy AA, Gadelmoula M, Elgammal MA, Osama E, Al-Hazmi H. Percutaneous nephrolithotomy in children: A preliminary report. Urol Ann 2014; 6: 187-191.

10. Li ZJ, Peng XY. Comparison of changes in serum inflammatory factors and red cell indices between laparoscopic cholecystectomy and small incision cholecystectomy. J Hainan Med Univ 2013; 19: 64-67.

11. Che XP, Wang LH, Xu L. Epidemiological characteristics of renal calculus in Hainan state farms. Chin J Clinic 2014; 8: 3307-3309.
12. Buldu I, Tepeler A, Karatag T. Combined micro-and standard percutaneous nephrolithotomy for complex renal calculi. Turk J Urol 2016; 42: 150-154.

13. Singh R, Kankalia S P, Sabale V. Comparative evaluation of upper versus lower calyceal approach in percutaneous nephrolithotomy for managing complex renal calculi. Urol Ann 2015; 7: 31-35.

14. Tian YH, Fan TY, Li LX. Comparison of the influence of different operation methods for the body stress and inflammatory state of patients with renal calculus. J Hainan Med Univ 2014; 20: 507-509.

15. Toda N, Nakanishi-Toda M. How mental stress affects endothelial function. Pflugers Arch 2011; 462: 779-794.

16. Staitieh B, Guidot D M. Noninfectious pulmonary complications of human immunodeficiency virus infection. Am J Med Sci 2014; 348: 502-511.

17. Budhiraja R, Siddiqi TA, Quan SF. Sleep disorders in chronic obstructive pulmonary disease: etiology, impact, and management. J Clin Sleep Med 2015; 11: 259-270.

18. Lu D, Jiang XL, Wu MH. Effects of ultrasonic adsorption lithotripsy by percutaneous nephroscope on inflammation mediators and stress hormones in patients with infectious renal calculi. J Hainan Med Univ 2016; 22: 680-682.

19. Zhang Y, Daaka Y. PGE2 promotes angiogenesis through EP4 and PKA C $\gamma$ pathway. Blood 2011; 118: 5355-5364.

20. Liu M, Gong Y, Wei JY. Media of rat macrophage NR8383 cells with prostaglandins E2-induced VEGF overexpression promotes migration and tube formation of human umbilical vein endothelial cells. J Southern Med Univ 2016; 36: 936-940.

21. Xiao WM, Wu BY, Chen XD. Effect of substance P on the human umbilical vein endothelial cells secreting and expressing nitric oxide. Fujian Med J 2005; 27: 144-146.

22. Zhang SF. Influence of thoracoscopic radical resection on pain stress and metabolic reaction in the treatment of patients with pulmonary carcinoma. J Clin Pulm Med 2015; 20: 413-415.

23. Shi TY, Ji YP, Xu YN. Protecting effects of aspirin on human aortic endothelial cells from inflammatory injury. Chin J Hosp Pharm 2016; 36: 1835-1838.

24. Cossette E, Cloutier I, Tardif K. Estradiol inhibits vascular endothelial cells pro-inflammatory activation induced by $\mathrm{C}$ reactive protein. Mol Cell Biochem 2013; 373: 137-147.

25. Zuo MH, Tang J. Effect of glutathione on oxidative stress, angiogenesis and immune function in patients with early chronic kidney disease in diabetes. Chinese J Diab 2015; 23: 973-977.

26. Huang $\mathrm{Zh}$, Lin SH. Study of protective effect of edaravone in treating renal injury caused by extracorporeal shock wave lithotripsy in renal calculi. Clinic Med J 2015; 13: 34-37.

27. Dong L U, Lei JX, Hui WM. Effects of ultrasonic adsorption lithotripsy by percutaneous nephroscope on inflammation mediators and stress hormones in patients with infectious renal calculi. J Hainan Med Univ 2016; 22: 680-682. 
28. Ge CL, Wang N. Content changes of NO, ET-1, LPO in cerebral cortex of vascular dementia in rats on TQHXD. Anhui Med Pharm J 2011; 15: 1063-1065.

29. Qiu CJ, Ao JS, Cheng L. Comparison of the curative effect and serum indexes of ultrasonic pneumatic and holmium laser technology for percutaneous nephrolithotomy treatment of complex renal calculus. J Hainan Med Univ 2017; 23: 779-781

30. Cui QF, Wu GY, Wang K. Effect of percutaneous renal lithotripsy on inflammatory mediators in patients with infectious kidney stones. Chin Heal Stand Manag 2016; 7: $55-56$.

\section{*Correspondence to}

Bao-hai Xu

Department of Urology

Ankang Central Hospital

PR China 